\title{
¿Qué pasado buscar? Visiones historiográficas chinas de antigüedad en los siglos V-III AEC
}

\section{What past to seek? Chinese historiographic views of antiquity in the V-III centuries BCE}

\author{
ANDRÉ BUENO \\ Universidad del Estado de Rio de Janeiro-UERJ, \\ Rio de Janeiro, Brasil \\ orientalismo@gmail.com
}

\begin{abstract}
Resumen: En este breve artículo pretendo discutir cómo algunos pensadores chinos de los siglos V-III AEC construyeron ideas sobre el pasado y el origen de la civilización, buscando justificar sus orientaciones filosóficas y su actividad política. Para ello, expondré cómo el monopolio del discurso del origen y desarrollo de la cultura se ha convertido en uno de los principales espacios de disputa y debate entre estas escuelas filosóficas. Utilizaré un conjunto de fragmentos de fuentes de este período para presentar estos puntos de vista, mostrando cómo reforzarían la idea de controlar la producción de discursos historiográficos en la antigua China. Palabras clave: confucianismo, taoísmo, moísmo, legalismo, historiografía china, sinología, Estados Guerreros.
\end{abstract}

Palabras clave: confucianismo, taoísmo, moísmo, legalismo, historiografía china, sinología, Estados Guerreros 
Abstract: In this short article, I intend to discuss how some Chinese thinkers from the V-III centuries BCE constructed ideas of the past and origin of civilization, seeking to justify their philosophical orientations and their political activity. For this, I will see how the monopoly on the discourse of origin and development of culture has become one of the main spaces of dispute and debate between these philosophical schools. I will use a set of fragments from sources from this period to present these views, showing how they would reinforce the idea of controlling the production of historiographical discourses in ancient China.

Keywords: Confucianism, Daoism, Mohism, Legalism, Chinese Historiography, Sinology, Warring States

Citar como: Bueno, A. (2022). ¿Qué pasado buscar? Visiones historiográficas chinas de antigüedad en los siglos V-III AEC. Revista Internacional de Estudios Asiáticos, 1(1), 70-96.

Fecha de recepción: 13-09-2021 | Fecha de aceptación: 13-10-2021 


\section{Introducción}

Según un comentario que he escuchado varias veces de historiadores chinos con quienes he tenido la oportunidad de hablar, a lo largo de los milenios, cuando los tiempos de hoy son buenos, el pasado se ve como malo o inferior; pero cuando las cosas no van bien hoy, el pasado se ve como una época mejor. La razón de este espejo invertido sobre el mismo pasado es la expresión de nuestro deseo interno de justificarnos históricamente nuestras actitudes y visiones del mundo.

La experiencia de mirar el pasado está indudablemente mediada por la forma en que entendemos el presente. Si bien buscamos evitar anacronismos o contradicciones, nuestra interpretación de hechos e imágenes de la antigüedad se basa en axiomas actuales, delineados por una u otra corriente teórica. Esta condición existía en la antigua China, y los antiguos gobiernos chinos mantuvieron una preocupación constante en producir versiones oficiales de las historias de sus estados. Esto no impidió, sin embargo, que distintas visiones sobre un mismo episodio resultaran en versiones absolutamente diferentes, derivadas de los proyectos de cada escuela de pensamiento y de sus autores.

En este texto, examinaré cómo algunos pensadores chinos han abordado la cuestión de la evolución histórica desde los orígenes de la civilización humana. Sorprendentemente, la preocupación con el origen del universo no estuvo presente en estas discusiones; ${ }^{1}$ los humanos emergieron en la historia desde el punto en que empezaron a recordar cosas y a narrar sus tradiciones sobre sí mismos, formando lo que más tarde se llamaría "cultura” (wen 文) y los “ritos” ( $l i$ 禮). En este punto, la historia (lishi 歷史) fue considerada el principal instrumento de transmisión de ideas y conceptos del pasado más remoto, y se convirtió en el centro de los debates que se formaron durante el período de los siglos V-III AEC.

Esta época convulsa fue marcada por el enfrentamiento de varias escuelas de pensamiento, que buscaban resolver los problemas sociales y

1 André Bueno, "China, uma civilização sem mitos de criação?", Sinotextos (2021): 65-81. 
políticos derivados de una peligrosa escalada de conflictos entre los estados chinos. El imperio Zhou 周朝 se dividió gradualmente en estados menores, que comenzaron a luchar por la supremacía, en un proceso que solo terminaría en 221 AEC con la reunificación del país y la formación de la dinastía Qin 秦朝. Este período se caracterizó por la intensa disputa de teorías e ideas, que buscaban formar nuevos proyectos políticos y, en el centro de estos debates, la historia estuvo presente como un espacio para la construcción de los discursos. ${ }^{2}$

\section{La historia como fuente de sabiduría}

En la antigüedad, la concepción china le dio un papel especial a la historia en la estructura cultural. La opinión de los pensadores era que la literatura histórica era un depósito de lecciones de sabiduría, la guardiana de ideas y costumbres. La producción de la historiografía china fue una de las más largas entre todas las civilizaciones del mundo, ${ }^{3}$ y reflejó esta preocupación por preservar y decodificar el pasado. Sin embargo, la percepción de la historia no se basó en una actitud meramente conservadora sobre la antigüedad; el análisis de las narrativas también pretendía responder a los dilemas morales y políticos de la época. Confucio 孔子 había dicho, en un pasaje muy conocido, que "un maestro es aquel que, a través de lo viejo, revela lo nuevo", ${ }^{4}$ denotando que el dominio de la historia era un conocimiento central para pensadores y políticos.

La tradición historiográfica china asume que surgió junto con la escritura en sí, en un tiempo sin fecha (presumiblemente en algún momento alrededor del tercer milenio AEC). El Wenxin Diaolong 文心雕龍 de Liu Xie 劉諰 (m. 522 EC), primer manual sobre literatura china, informa lo siguiente:

2 Lin Xiaoping 林晓平, “春秋战国时期史官职责与史学传统”, 史学理论研 究, n.1 (2003): 59-69.

3 Leon Vandermeersch, Études Sinologiques. (Paris, Presses Universités de France, 1994), 315-330.

4 Confucio 孔子, Lunyu 論語, cap. 為政, 11. [Traducción propia] 
En los tiempos de Xuanyuan 軒轅 (el Emperador Amarillo 黄帝), Cangjie 倉頴 fue historiógrafo. El cargo oficial de ocuparse de los textos viene ya de tan antiguo. El Quli 曲禮 dice; 'los historiógrafos (preparan) pinceles para tomar nota'. Historiar significa 'comisionar'. Historiógrafos son los que, a derecha o izquierda (del soberano) están comisionados para llevar los registros. En el pasado, el de la izquierda recogía los hechos, y el de la derecha las palabras. El clásico de las palabras es el Shangshu 尚書 (Shujing 書經), y de los hechos es el Chunqiu 春秋.5

Este breve pasaje explica, dentro de la tradición china, cuándo y cómo se formó el comienzo de la historiografía china y su sistema de funcionamiento. Personajes como Xuanyuan (también conocido como Huangdi , o 'Emperador Amarillo', que habría vivido entre 2711-2597 AEC) y Cangjie, conocido como el creador del sistema de escritura, son probablemente figuras míticas; pero el sistema de anotar eventos y fechas está corroborado por las inscripciones hechas en huesos usados como oráculos durante el período Shang, ${ }^{6}$ y por el formato de las dos fuentes principales sobre la antigüedad china, el Libro de Historias (Shujing 書經) y Primaveras y otoños (Chunqiu 春秋). El primer texto trajo los principales acontecimientos y personajes de la historia china hasta el período temprano de la dinastía Zhou, y consistió en una serie de largas descripciones en prosa de ciertos episodios y discursos, en cuanto Primaveras y otoños, constaba de una cronología seca y sencilla, que informaba las fechas de ciertos eventos y breves comentarios al respecto. Como sabemos hoy, hubo una gramatología que involucró la construcción de conceptos y vocabularios históricos en la descripción de estos hechos, lo que hizo de su escritura e interpretación un proceso permeado por tensiones políticas e intelectuales. ${ }^{7}$ Aunque la versión más conocida de este texto que tenemos es la de Confucio, quien describió las fechas clave en la historia de su tierra natal,

5 Liu Xie, Wenxin Diaolong 文心雕龍, cap. 史傳, 1. [Traducción de Alicia Relinque Eleta]

6 David Keightley, Sources of Shang History: The Oracle Bone Inscriptions of Bronze Age China (Berkeley, University of California Press, 1985).

7 André Bueno, "Não invento, apenas transmito': reinterpretando a escrita historiográfica de Confúcio", en Anais da X Semana de História Politica da UERJ, (Rio de Janeiro, 2015), 251-260. 
Lu 魯國, a lo largo del siglo VI AEC, otros estados produjeron sus propias crónicas, ${ }^{8}$ presentando diferentes visiones sobre los mismos hechos.

Para los chinos, era relevante entender que, en los albores de la producción textual de su civilización, la Historia era una de las narrativas cruciales para la preservación de la cultura. El historiador (taishi 太史) se encargaba de registrar las memorias del Estado, así como dominar el calendario y los fenómenos astronómicos (utilizados para determinar y regular las actividades laborales anuales). Del análisis realizado se infería la comprensión intelectual de los hechos históricos y sus lecciones morales y científicas. Se esperaba, por tanto, que el historiador pudiera aprehender el principio que subyace en los hechos, aclarando sus situaciones y tendencias. Xunzi 荀子 (314-217 AEC) afirmó que todo conocimiento proviene de la naturaleza humana, y solo ella podría conocer los principios de las cosas. ${ }^{9}$ Siglos después, Zhuxi 朱喜 (1130-1200), uno de los grandes autores de lo movimiento neoconfuciano, desarrolló este punto de vista, defendiendo que los sabios del pasado buscaron en el estudio de los principios ( $l i$ 理) el entendimiento necesario para practicar los valores éticos; ${ }^{10}$ bumanidad o benevolencia (ren 仁), rectitud ( $y i$ 義), ritos ( $l i$ 禮), fidelidad ( $x$ in 信) y sabiduria ( $z h i$ 智). Estas afirmaciones partían de la idea de que la comprensión del pasado implicaba el entendimiento de ciertas claves y fenómenos que impregnaron los eventos, y que muchas veces solo podían ser percibidos por los buscadores de la sabiduría. Por otro lado, estas mismas ideas podrían traducirse en la redacción de narrativas históricas, para construir una literatura moral y reflexiva. Por eso, la narración de hechos ya traía, en sí misma, mensajes a decodificar; y, en consecuencia, la escritura histórica incluyó la propia comprensión de los historiógrafos sobre

8 Además de los comentarios de Gongyang 公羊 傳, Guliang 穀 梁傳 y Zuo 左 氏 傳, también existen otras versiones conocidas, como Wu Yue Chunqiu 吴越春 秋 y Yanzi Chunqiu 晏子春秋.

$9 X u n z i$ 䓎子, cap. 解蔽, 12-15.

10 André Bueno, Cem textos de História Chinesa (União da Vitória, Projeto Orientalismo, 2011), 61-63. 
los temas en cuestión, a los cuales impusieron sus concepciones teóricas e interpretativas. ${ }^{11}$

Estos problemas están directamente presentes en el análisis de los fragmentos que veremos a continuación. En el período en cuestión, del siglo $\mathrm{V}$ al III AEC, los pensadores chinos fueron capaces de proponer diferentes interpretaciones para eventos comunes, respondiendo a una demanda específica de sus escuelas. Dado que la mayoría de los intelectuales de esa época estaban involucrados en temas políticos, sus versiones probablemente apuntaban a algún tipo de preponderancia sobre otras; aun así, es notable que los chinos de entonces ya admitían la diversidad de ideas en el debate histórico, en contraposición a la creencia de las narrativas unívocas.

\section{La génesis de la civilización como centro de un problema}

Entre los siglos VI y IV AEC, los estados chinos se vieron cada vez más involucrados en una serie de conflictos intermitentes, lo que provocó una sensación de decadencia y agotamiento de sus instituciones políticas y culturales. Fue una época de guerras, intrigas y la 'disolución de costumbres', en la opinión de los historiadores de esta época. ${ }^{12}$ El surgimiento de las escuelas de pensamiento (jia 家) que se produce a partir de esta situación ya ha sido bien presentado por otros autores como Anne Cheng ${ }^{13} \mathrm{y}$ Brian Norden. ${ }^{14}$ La consulta de estos materiales es de relevancia para la objetividad de este estudio.

Me gustaría centrarme en el análisis del problema del 'origen' (o los 'tiempos ancestrales', gudai 古代) de la civilización china, y cómo algunos pensadores de ese período entendieron su evolución histórica y

11 François Jullien, A propensão das coisas: por uma história da eficácia na China. (São Paulo, Ed. UNESP, 2017), 223-284.

12 Jean Levi, Los funcionários divinos. (Madrid, Alianza, 1991), 17-58.

13 Anne Cheng, História do Pensamento Chinês. (Petrópolis, Vozes, 2009) 63$100,208-235$ y 262-280.

14 Brian Norden, Introdução a filosofia chinesa clássica (Petrópolis, Vozes, 2018). 
cultural. Es importante tomarr en cuenta que los chinos no tenían interés en la arché apxý del universo, pues estaba asentada la cosmología creativa del libro de los cambios (Yijing 易經)., El Shujing, por su parte, comienza en el momento de las dinastías Xia 夏 y Shang 商, ignorando solemnemente cualquier preocupación por el problema de la génesis. ${ }^{15}$ En el Libro de los Ritos (Liji) consiste en una enciclopedia histórica de las prácticas, ideas y costumbres chinas, lo que permite encontrar informaciones sobre cómo estos pensadores imaginaban los períodos más remotos de su pasado. Como se verá más adelante, las descripciones chinas de los albores de la humanidad se basaron en observaciones antropológicas de comunidades rurales. En las aldeas fronterizas, donde aún no existía la preocupación por la urbanidad, la cultura o la escritura, los intelectuales chinos creían que estos pueblos habían mantenido una forma más 'primitiva' de la vida, heredada directamente del pasado. ¿Y cómo estas comunidades un día se convirtieron en ciudades urbanizadas, regidas por las leyes y los funcionarios, donde se pueden practicar la escritura, la música y las artes plásticas? El vacío que había creado la falta de correspondencia entre lo 'urbano' y 'rural', lo 'nuevo' y lo 'primitivo', fue la clave para entender dónde había fracasado la 'evolución' cultural, que había hecho surgir los problemas sociales y morales que afligían el mundo chino.

\section{La percepción de Confucio}

Confucio (551-479 AEC) fue el primer pensador en tener una clara preocupación por lo que él entendía como decadencia cultural. Su visión del pasado afirmaba que la civilización se había desarrollado gracias a la transmisión y preservación de ritos, necesarios para el establecimiento del orden, la moral y el gobierno. Por tanto, su proyecto de salvación para la sociedad (su camino o método, dao 道) se fundó en una reforma educativa integral, basada en un programa de enseñanza ética, que capacitaría tanto a los administradores públicos para ser mejores gobernantes como a las personas para ser mejores ciudadanos. Por lo tanto, su comprensión del pasado fue consciente de la importancia del proceso de desarrollo

15 Bueno, "China, uma civilização", 65-67. 
cultural, que permitiría el crecimiento de la sociedad y su refinamiento. ${ }^{16}$ Para ejemplificar esta idea, como se mencionó, citaré un pasaje de Liji, un texto cuya autoría se atribuyó a Confucio, pero que fue recuperado durante la dinastía Han 漢朝. Soy consciente de las discusiones que proponen que el Liji llegaría más tarde, y que no se habría producido a partir de las palabras de Confucio; ${ }^{17}$ sin embargo, opto por la teoría que propone que las ideas presentes en el texto son realmente del viejo maestro, ya que se encuentran, precisamente, con el problema del monopolio histórico de los orígenes, tema que será discutido. ${ }^{18}$ Además, los siguientes pasajes dialogan directamente con los fragmentos que serán presentados de otras escuelas, lo que puede indicar su producción en el contexto temporal definido. Por lo tanto, acepto aquí que las ideas presentadas en los pasajes seleccionados representan, de alguna manera, el pensamiento de Confucio y sus seguidores en el período pre-Han. Así, según Confucio, en la antigüedad,

al principio, en el uso de las ceremonias, se comenzaba con la carne y la bebida. Asaban el mijo y pedazos de puerco; excavaban la tierra en forma de un tarro, y sacaban el agua de allí con las dos manos; formaban una manija de arcilla, y golpeaban con ella un tambor terrestre. Tan simples como eran estos arreglos, ellos, sin embargo, parecían poder expresar a través de los mismos su reverencia por los seres espirituales. 'Esto y lo otro', cuando alguien moría, subían al techo y decían en voz alta su nombre en una nota prolongada,

16 Para las cuestiones historiográficas en Confucio, ver, Ng On-Cho y Edward Wang, Mirroring the past: the writing and use of history in imperial China. (Honolulu, University of Hawai Press, 2005), 1-79.

17 Pei Chuanyong 裴传永, “大同小康之论非关孔子辨”, 孔子研究, n.6, (2003): 12-21; Pei Chuanyong 裴传永, “大同小康之论提出者诸说辨误”, 孔 子研究, n.2 (2020): 97-108.

18 Gai Litao 盖立涛, “道治与礼治之间—《礼记. 礼运》篇大同小康关系 新论”, 哲学动态, n.5, (2017): 50-55; Yang Xiaoming 杨朝明, “《礼运》大同 说的实质与意义”, 衡水学院学报, n.6, (2016); Wu Fei 吴飞, “《礼运》首章 再考辨” 传统中国研究集刊, n.19(2018); Guo Qiyong 郭齐勇, “《礼记》哲 学诠释的四个向度一以《礼运》, 《王制》为中心的讨论”, 复旦学报: 社会科学版, n.1 (2016): 41-53. 
diciendo, 'regresa, tal y cual'. Después de esto, llenaban la boca del muerto con arroz crudo y arreglaban como ofrendas paquetes de carne cruda. De este modo, miraban al Cielo, a donde el espíritu se había ido, y enterraban el cuerpo en la tierra. El cuerpo y el alma animal van hacia abajo, mientras que el espíritu inteligente va hacia arriba. Del mismo modo, los muertos eran colocados con sus cabezas hacia el norte, mientras que los vivos miraban hacia el sur. En todos estos asuntos se seguían las costumbres más antiguas. Anteriormente, los reyes antiguos no tenían una casa. En invierno, vivían en cuevas que habían excavado, y en verano, en nidos que habían confeccionado. No conocían aún el poder transformante del fuego, sino que comían frutas de plantas y árboles, así como la carne de pájaros y bestias; bebían su sangre, y tragaban también el pelo y las plumas. No conocían todavía el uso del lino y de la seda, sino que se vestían con plumas y pieles. Los antiguos sabios surgieron entonces, $\mathrm{y}$ los hombres aprendieron a aprovechar los beneficios del fuego. Moldearon los metales y trabajaron la arcilla, de modo de levantar torres con estructuras en ellas, y casas con ventanas y puertas. Tostaron, asaron, hirvieron y cocinaron en parrillas. Produjeron mosto y salsas. Trataron el lino y la seda para formar telas de lino y seda. Pudieron, así, alimentar a los vivos y hacer ofrendas a los muertos para servir a los espíritus de los difuntos y a la divinidad. En todos estos aspectos seguimos el ejemplo de ese lejano tiempo. De esta manera es que el licor de color oscuro está en el apartamento donde se encuentra ocupado el representante del muerto; que el recipiente de mosto se halla cerca de la puerta de entrada; que el licor rojizo se ubica en el pasillo, y el claro en el patio de abajo. Las víctimas también son exhibidas, y los trípodes y los soportes están preparados. Los laúdes y las cítaras se ponen en sus lugares, con las flautas, las piedras sonoras, las campanas y los tambores. Los rezos del principal en el sacrificio a los espíritus, y las bendiciones de los representantes del difunto, se establecen cuidadosamente. El objeto de todas las ceremonias era atraer hacia abajo a los espíritus desde arriba, incluso a los ancestros, sirviendo, también, para rectificar las relaciones entre el gobernante y los ministros; para mantener el sentimiento de generosidad entre el padre y el hijo y la armonía entre el hermano mayor y el menor; para ajustar las relaciones entre lo alto y lo bajo, y para conferir sus lugares apropiados al esposo y la esposa. Todo el conjunto se puede decir que se daba para asegurar la bendición del Cielo. ${ }^{19}$

Como puede verse, esta descripción es muy similar a las concepciones actuales acerca de las condiciones de vida entre el Meso y el Neolítico. Es importante recordar que el proceso de desarrollo de las civilizaciones no es

19 Liji, cap. 禮運, 5-10 [Traducción de Fulvio Scarcia y Leonardo La Rosa] 
uniforme, sino que hay importantes variaciones espacio-temporales. Esto permite corroborar la idea de la presencia de asentamientos 'primitivos', que inspiró Confucio a creer que así vivían sus antepasados, y que el ascenso de los sabios había promovido el gran movimiento de evolución cultural. Este proceso, sin embargo, vino naturalmente acompañado de algunos problemas. En la idealización de Confucio, las sociedades más simples eran más fáciles de manejar, pero también enfrentaban un mayor número de adversidades. Por ello, la trayectoria de la civilización china se encontraba en una nueva fase de estancamiento:

Cuando el Gran Curso era seguido, un espíritu público y común gobernaba todo bajo del cielo; ellos elegían hombres de talento, de virtud y de capacidad; sus palabras eran sinceras, y lo que cultivaban era la armonía. Así, los hombres no amaban sólo a sus padres, ni trataban como niños únicamente a sus propios hijos. Provisiones suficientes eran aseguradas para los ancianos hasta su muerte, así como el empleo para los hombres saludables y los medios para el crecimiento de los jóvenes. Ellos mostraban amabilidad y compasión por las viudas, los huérfanos, los hombres sin hijos y por aquellos que estaban discapacitados por alguna enfermedad, de modo que todos fueran mantenidos suficientemente. Los varones tenían su propio trabajo, y las mujeres tenían sus hogares. Acumulaban artículos de valor, desechando aquellos que debían ser arrojados al piso, sin desear guardarlos para su propia gratificación. Trabajan con su fuerza, desechando la que no debía ser llevada a cabo, pero no ejerciéndola solamente con objeto de su propia ventaja. De esta manera, los intrigantes egoístas eran reprimidos y no encontraban ningún desarrollo. Ladrones, estafadores y traidores rebeldes no se mostraban y, por lo tanto, las puertas externas seguían abiertas, y no eran cerradas. Esto ocurrió en el periodo que llamamos de la Gran Unión 大同. Ahora que el Gran Curso ha caído en el olvido y la oscuridad, el reino es una herencia familiar. Cada uno ama, por encima de los demás, a sus propios padres, y acaricia como nińos solamente a sus propios hijos. La gente acumula artículos y ejerce su fuerza para su propia ventaja. Los grandes hombres se imaginan que es norma que su Estado deba descender hasta sus propias familias. Su objeto es hacer fuertes los muros de sus ciudades y suburbios, así como sus zanjas y fosas seguras. Las reglas de propiedad y de lo que es correcto se observan como los hilos con los cuales se intenta mantener en su forma correcta la relación entre el gobernante y el ministro; en su generoso respeto aquella entre el padre y el hijo; en su armonía esa entre un hermano mayor y uno más joven; y en una comunidad de sentimientos, la relación entre el marido y la esposa. De acuerdo con ellos se delimitan edificios y medidas, se establecen los campos y las aldeas para las viviendas de los campesinos, se decreta la 
superioridad de los hombres valiosos y sabios, y se regulan sus logros con la finalidad de su propia ventaja. Así que los esquemas y las empresas egoístas están alzándose constantemente, y el recurso es siempre el de las armas; fue de este modo también como Yu, Tang, Wen y Wu, el rey Kang, y el duque de Zhou obtuvieron sus distinciones. De estos seis grandes hombres, cada cual estaba muy atento a las reglas de propiedad, para así asegurar la exhibición de la rectitud, la realización de la sinceridad, la exposición de los errores, la ejemplificación de la benevolencia, y la discusión de la cortesía, mostrando a la gente todas las virtudes normales. Cualquier gobernante que no siguiera este curso era conducido lejos por aquellos que poseían poder y posición, y todos lo miraban como un parásito. Este es el período que llamamos la Pequeña Tranquilidad 小康. ${ }^{20}$

Como se puede ver, Confucio creía que la base del equilibrio social radicaba en el mantenimiento de las prácticas culturales (generalmente llamadas 'ritos' por los sinólogos del siglo XIX), que solo podían continuar existiendo con un programa educativo activo. La enseñanza (jiao 教) fue el concepto central de las estrategias de difusión del conocimiento confuciano, que virtualmente podría restaurar y mantener el período de Paz Menor. Por esta razón, la escuela de Confucio se llamaría Rujia 儒家, o 'Escuela de los Letrados', ya que estaría orientada a la formación de profesores y funcionarios gubernamentales. En este sentido, la enseñanza de la historia (lishi 歷史) se consideró fundamental para comprender el proceso de cambio en la sociedad. Incluso en su época, Confucio se quejó de la ausencia de fuentes y documentos para conocer mejor la antigüedad, ${ }^{21}$ lo que constituyó un desafío para observar las transformaciones en el tiempo y la cultura. La división en dos grandes edades, como se destaca en el fragmento, proponía la existencia de un período en el que la vida era más simple (coincidiendo con la época 'primitiva') y, por lo tanto, de gran 'armonía' (he 和); el desarrollo de la civilización trajo un cambio sustancial en la calidad de vida, pero también transformó los sentimientos humanos, que debían ser disciplinados por los ritos $(l i)$. Este proceso parece inevitable, ya que los chinos tuvieron que enfrentar varios desafíos a lo largo de

20 Ibíd., Liji, cap. 禮運, 1-2 [Traducción de Fulvio Scarcia y Leonardo La Rosa] 21 Confucio, Lunyu 論語, cap. 八佾, 9. [Traducción propia] 
su existencia, como la gran inundación, ${ }^{22}$ en la que se impusieron desafíos técnicos y éticos a la forma de vida sencilla y despreocupada. La complejidad de la sociedad, en consecuencia, requería respuestas más profundas y elaboradas, derivadas de la investigación histórica y la reflexión ética. Para Confucio, por lo tanto, era crucial rescatar el pasado, pero también aceptar que los tiempos estaban cambiando, y que era necesario preparar un futuro mejor.

\section{Vuelta a la simplicidad, renunciar al mundo}

En sentido contrario a Confucio, los seguidores del pensador Laozi 老 子 (siglo $6 \mathrm{AEC}$ ) propusieron que el problema era, exactamente, la Cultura. Toda la decadencia y la violencia en la sociedad se derivaban de la artificialidad de las relaciones humanas, que se habían desconectado de su naturaleza original (ziran 自然). Era imposible que un sistema funcionara si se basaba en los ritos y las leyes creadas por la propia gente. La naturaleza misma había asignado un curso específico a la especie humana y esta se había desviado de él. ${ }^{23}$

El retorno a una sociedad sana supuso, por tanto, el abandono indispensable de la cultura imperante y el retorno a la vida sencilla de los orígenes. Aparentemente, Laozi y los daoístas se inspiraron precisamente en estos pueblos tranquilos del campo y los consideraron el modelo ideal, plausible de realizarse, y lo más cercano posible a una sociedad sin las complejidades de la civilización:

Antaño quienes sabían practicar el Tao no usaban de él para ilustrar a las gentes, sino para mantenerlas en la ignorancia.

Si el pueblo es difícil de gobernar, es porque sus conocimientos son muchos.

Por eso quien gobierna el Estado usando de la inteligencia es un bandido para el Estado;

22 Shujing, cap. 堯典, 3 e cap. 舜典, 9. [Traducción propia] 23 Zhang Weyan 张文彦, “论先秦儒家与道家的自然观及历史观”. 史学理 论研究 n.3 (2003): 61-65. 
gobernar el Estado sin usar de la inteligencia

es (traer) la felicidad al Estado;

tener presentes estas dos razones

es también una norma principal.

Tener siempre presente esta norma universal,

a eso llaman «misteriosa virtud».

La virtud misteriosa es profunda y vasta,

junto con las cosas retorna (al Tao),

y después alcanza la gran armonía (con la Naturaleza) ${ }^{24}$

En opinión de esta escuela, por tanto, los sabios (en el sentido confuciano) habían contribuido directamente a degradar la humanidad, con valores artificiales y la preservación de ritos que desvían a las personas de su espontaneidad existencial. El sabio daoísta debería pretender precisamente lo contrario, ${ }^{25}$ basado en una acción libre de propósitos humanos (wuwei 無為) pero encaminada a armonizar con los movimientos de la naturaleza y la voluntad de las personas:

¿Por qué el Río y el mar pueden ser reyes de (las aguas) de cientos de valles?

Porque saben estar por debajo de ellos, y de ahí que sobre cientos de valles sean capaces de reinar.

Por eso cuando se desea estar encima de las gentes

es menester abajarse ante ellas en las palabras, y cuando se desea andar delante de las gentes es menester ponerse a su zaga.

Por eso el sabio está encima sin que las gentes sientan su peso, y delante sin que las gentes sientan daño. ${ }^{26}$

Zhuangzi 莊子 (369-286 AEC), uno de los más representativos autores de esta escuela, apoyó las ideas de Laozi, manteniendo el mismo discurso sobre el tema de los orígenes de las personas y la distorsión provocada por los sabios:

24 Laozi, Daodejing 道德經, cap. 65 [Traducción de Iñaki Preciado Idoeta]

25 Jiang Chongyue 蒋重跃, “辩证发展观在古代中国的觉醒一道儒两家 以'反为主题的理论探索”, 南京大学学报: 哲学. 人文科学. 社会科学, n.5 (2015) 64-74.

26 Laozi, Daodejing, cap. 66. [Traducción de Iñaki Preciado Idoeta] 
Por eso, en los tiempos de la perfecta virtud los hombres caminaban pausadamente, y su mirada era franca y sencilla. En esa época no había senderos ni minas en las montañas, ni sobre las aguas barcos o puentes. Los millones de seres se multiplicaban y vivían cerca unos de otros. [...] En los tiempos de la perfecta virtud los hombres moraban en compañía de las aves y de las bestias, y con todos los seres juntos vivían; ¿cómo, pues, habrían podido distinguir entre el hombre de honor y el hombre vulgar? Iguales en la ausencia de conocimiento, todos vivían conforme a su propia naturaleza; iguales en la ausencia de ambiciones, todos eran puros y sencillos. Siendo puros y sencillos, se podía preservar la naturaleza de las gentes. Aparecieron los sabios, y se esforzaron en practicar la benevolencia y se desvivieron por ejercitar la justicia; y fue entonces cuando la confusión empezó a reinar en el mundo. Ablandaron a los hombres con la música y los complicaron con los ritos, y fue entonces cuando las divisiones empezaron a surgir en el mundo. [...] arruinar el Tao y su virtud es el crimen del sabio. ${ }^{27}$

Como podemos ver, el discurso sobre el pasado traduce la antigüedad como un período de pureza y austeridad; la historia, entonces sería un recurso para la comprensión de cómo los seres se desviaron de un modelo original, un breve testimonio de la decadencia humana; volver a los orígenes, antes de la construcción de la cultura, era esencial para la supervivencia, incluso si el costo era la destrucción de las ciudades y de todo conocimiento.

\section{Fin de la Cultura, pero solo la de la élite...}

Uno de los oponentes más importantes de Confucio y Laozi fue Mozi 墨子 (470-391 AEC), pensador que defendía un ideal comunitario y participativo de la sociedad. Para él, la historia reveló que desde la antigüedad los sabios se preocuparon por mejorar la vida de las personas, pero estos propósitos se fueron perdiendo gradualmente. ${ }^{28}$ Poco a poco, se fue formando una élite a partir de la división de poderes y clases sociales, que mantenía el monopolio de la vida política y envolvía a los humildes en sus

27 Zhuangzi 莊子, Libro IX, cap. 馬蹄, 1 [Traducción de Ińaki Preciado Idoeta], 107.

28 Cui Qingtan 崔清田, “论墨子学说的体系与中心”, 晋阳学刊, n.6 (2001): 66-71. 
conflictos privados. En su interpretación del pasado, Mozi argumentó lo siguiente:

Dice Mo Ti: En los tiempos primitivos, cuando comenzó a haber hombres y aún no existía ni gobierno ni tribunales de justicia, las palabras de unos tenían significación diversa de las de otros. Cada uno tenía su idea; dos tenían dos ideas; diez, diez ideas. Tantas ideas como número de hombres. Cada uno tenía por verdadera su idea y por falsas las ideas de los demás. Mutuamente se condenaban. Dentro de cada familia había reyertas y odios entre padres e hijos y se dispersaban por no poder convivir en unión y paz. Las gentes del mundo se hacían unos a otros daños con agua, fuego y venenos. Quienes tenían fuerza de sobra no querían emplearla para ayudar a otros. Dejaban que se les pudrieran los géneros que les sobraban, por no distribuirlos con los demás. Ocultaban las buenas ideas o doctrinas por no ensenárselas a otros. El desorden reinaba en el mundo. Se comportaban como fieras. Entonces, cayeron en la cuenta de que el desorden provenía de que no tenían superiores que los gobernaban y decidieron que sería mejor elegir al mejor de ellos. Le eligieron con el título de 'Hijo del Cielo'. Constituido el emperador, vieron que sus fuerzas no bastaban y les pareció que sería bueno elegir los mejores del mundo y establecer tres ministros. Erigidos el emperador con sus tres ministros, vieron la inmensa extensión del territorio y los pueblos diferentes de tierras muy distanciadas entre sí y la imposibilidad de que uno o dos hombres pudieran discernir entre la verdad y la falsedad, provecho o daño. Dividieron diez mil comarcas y erigieron a los señores feudales para regentes de estos estados. Constituidos regentes los señores feudales, se vio también que sus fuerzas tampoco bastaban y se eligieron en sus estados los mejores y se les constituyó para gobernadores. Erigidos los gobernadores, el emperador promulgó en el imperio su programa político. [...] De esta manera, ¿cómo se podrá decir que reina el desorden en el imperio? Si, pues, examinamos de qué depende el orden y paz del Imperio, veremos que el emperador es el Único capaz de unificar y acordar los pareceres todos del imperio. Con esto, reinará el orden y la paz en el imperio. ${ }^{29}$

Sin embargo, los gobernantes perdieron la moral a lo largo de la historia, y cedieron a las tentaciones del poder, tomando un camino de egoísmo, ambición y violencia:

Los grandes magnates y prefectos aman sus propias familias o casas y no aman las de los otros y revuelven las casas de los demás en beneficio propio. Los señores feudales aman sus propios estados y no aman los estados de los

29 Mozi 墨子, Libro III, cap.11. [Traducción de Carmelo Elorduy] 
demás y atacan los estados de los vecinos en beneficio de sus propios estados. Esta, y solamente ésta, es la causa de la anarquía reinante en el mundo. Hoy, los señores feudales solo han aprendido a apreciar sus estados y no los de los demás. No tiene reparos en atacar a los estados limítrofes. ${ }^{30}$

Para resolver esto, sería fundamental que el soberano pudiera interceder, sirviendo directamente a sus súbditos, y no a los intereses privados de los nobles. Fue la cultura de élite que oprimió a la gente; para superarla, se necesitaba otro recurso innovador. Mozi creía que las diferencias entre seres que se habían creado a lo largo de la historia, podían anularse y resolverse solo mediante el amor universal (jian ai 兼爱) ${ }^{31}$ Aunque Mozi compartió la regla de oro con Confucio ('no hagas a los demás lo que no quieres para ti'), el amor se convirtió en un elemento activo en la transformación del pasado, creando una nueva perspectiva sobre las relaciones humanas:

Si se mira la casa del otro como su propia casa, ¿quién se pondría a revolverla? Si se mirase el estado de otro como su propio estado, ¿quién iría a atacarlo? El revolver los grandes prefectos las casas de sus vecinos y el atacarse mutuamente los señores feudales desaparecería completamente. Si se lograra que todos en el mundo se amaran mutuamente, no habría estados que agredieran a otros estados; las casas o los clanes no se revolverían mutuamente; no habría bandidaje. Entre rey y sus ministros, entre padres e hijos reinaría la piedad y el amor recíprocos. Así, el mundo gozaría de orden y paz. Los santos varones, que se aplicaron a restablecer el orden en el mundo, ¿cómo no habían de prohibir el odio y fomentar el amor? El mundo gozará de orden y paz cuando los hombres todos se amen mutuamente y estará revuelto mientras reine el odio mutuo. Esta es la razón por la que Mo Ti dice que es menester exhortar a practicar el amor a los demás. ${ }^{32}$

La relectura del pasado de Mozi invocó la idea de una antigüedad igualmente idealizada, pero no necesariamente perfecta. La cultura letrada (o 'confuciana') era la imagen del sistema de desigualdad y opresión que se

30 Mozi墨子, Libro IV, cap.14. [Traducción de Carmelo Elorduy]

31 Huang Bo 黄勃, “论墨子的”兼爱”, 湖北大学学报: 哲学社会科学版, n.4 (1995): 78-85; Qian Yongshen 钱永生, “墨子人本思想的结构”, 《湖南 大学学报: 社会科学版》, n.1 (2009): 5-10.

32 Mozi 墨子, Libro IV, cap. 14. [Traducción de Carmelo Elorduy] 
había impuesto a la civilización a lo largo de los siglos; pero volver a una sociedad tribal como proponían los daoístas parecía simplemente inviable, ya que los seres humanos buscaban desarrollarse en relación con la naturaleza. El problema central para comprender los orígenes, por tanto, se dirigió a cómo preservar la sociedad de la desigualdad, a través de sentimientos de altruismo e igualdad (o amor universal) que pudieran anular las diferencias de 'clase'.

\section{¿Abolir la historia?}

A partir de estos mismos materiales históricos, la Escuela de las Leyes o Legalismo (Fajia 法家) pensó en la interpretación de la antigüedad como la contemplación de una trayectoria de evolución y desarrollo de la cultura, en la cual el ser humano juega un papel fundamental. Se crearon leyes para imponer orden en el mundo; y cuanto más complejo fuera el mundo, se necesitarían más leyes. ${ }^{33}$ Como animal más inteligente de la naturaleza y productor de la civilización, el ser humano podría imponer una nueva armonía a la naturaleza, estableciendo medios más eficaces para gobernarla. Pensadores como Shang Yang 商鞅 (390-338 AEC) y Hanfeizi 韓非 子 (280-233 AEC) imaginaron que esta sería la respuesta a los dilemas de su tiempo, con la formación de un estado centralizado, fuerte y unificado que prohibiría el desacuerdo y castigaría la diferencia. Al hacerlo, esperaban estandarizar la civilización, anulando las distinciones y creando una sociedad orgánica basada en reglas y administrada por la burocracia. De esta manera, Shang Yang propuso que leer las eras antiguas de la historia china incluía un esfuerzo gradual por controlar la naturaleza y la sociedad:

Of old, in the times of the Great and Illustrious Ruler, people found their livelihood by cutting trees and slaying animals; the population was sparse, and trees and animals numerous. In the times of Huang-di, neither young animals nor eggs were taken; the officials had no provisions, and when the people died, they were not allowed to use outer coffins. These measures were not the same, but that they both attained supremacy was due to the fact that the times in which they lived were different. In the times of Shen-nong 神農, men ploughed to obtain food, and women wove to obtain clothing.

33 Zeng Zhenyu 曾振宇, “商鞅法哲学研究”, 史学月刊, n.6 (2000): 26-33. 
Without the application of punishments or governmental measures, order prevailed; without the raising of mailed soldiers, he reigned supreme. After Shen-nong had died, the weak were conquered by force and the few oppressed by the many. Therefore Huang-di created the ideas of prince and minister, of superior and inferior, the rites between father and son, between elder and younger brothers, the union between husband and wife, and between consort and mate. At home, he applied sword and saw, and abroad he used mailed soldiers; this was because the times had changed. Looking at it from this point of view, Shen-nong is not higher than Huang-di, but the reason that his name was honoured was because he suited his time. ${ }^{34}$

Es notable que, en este caso, a pesar de que la antigüedad fue idílica (condición presente en las otras narrativas que hemos visto hasta ahora), la evolución de la sociedad condujo a la creación de leyes, divisiones y costumbres. Sin embargo, donde Confucio vio la educación como una forma de restaurar las prácticas sociales $(l i)$, los legalistas defendieron la necesidad de imponer la fuerza y la ley $(f a)$ como un instrumento necesario de equilibrio de fuerzas. ${ }^{35} \mathrm{La}$ frase 'the few oppressed by the many' revela claramente el temor por la fuerza del pueblo hacia las élites gobernantes. Shang había afirmado que "a good ruler obstructed the people by means of the law, and so his reputation and his territory flourished" . ${ }^{36}$ En su lectura, el periodo de confrontación en que vivía mostró que cuando los gobiernos pierden el control, la civilización pierde el curso. Por tanto, era fundamental determinar límites y mecanismos de control para que la sociedad siguiera funcionando; y finalmente, asentar las bases de una nueva forma de Estado: "Therefore a sage, if he is able to strengthen the state thereby, does not model himself on antiquity, and if he is able to benefit the people thereby, does not adhere to the established rites". ${ }^{37}$

En este sentido, el pensador Hanfeizi fue más allá de Shang Yang; para él, mientras recurrimos a la historia y las tradiciones para justificar los modelos del presente, nos mantendríamos atascados en nociones antiguas

34 Shang Junshu 商君書, cap. 畫策, 1. [Traducción de J. J. L. Duyvendak] 35 Sui Shufen 隋淑芬, “法治社会的建构——论商鞅的社会理想”, 贵州社 会科学, n.6(2005): 58-61.

36 ShangJunshu, cap. 弱民, 1. [Traducción de J. J. L. Duyvendak] 37 ShangJunshu, cap. 更法, 3. [Traducción de J. J. L. Duyvendak] 
que ya no nos servirían de nada. ${ }^{38}$ Dentro de la lógica de esta escuela, observar la historia sería entender cómo sucedieron las cosas, pero también entender que esta antigüedad se fue, y se necesitaban nuevas respuestas para nuevos tiempos:

Los grandes hombres actuales no serían diferentes: también se reirían de todo aquel que alentase el uso de métodos anticuados, semejantes a los de los reyes modelo Yao, Shun, Tang, Wu o Yu, pues los grandes hombres no atienden a épocas antiguas ni siguen patrones prefijados, sino que inventan soluciones apropiadas a cada tiempo y asunto, tras examinarlo. ${ }^{39}$

Una solución radical sería abolir la historia y reescribirla desde un nuevo hito fundador, el estado centralizado propuesto por Qin. ${ }^{40}$ Emplear la retórica del pasado seguiría siendo una respuesta inútil para la época contemporánea:

Puesto que ni las costumbres antiguas se parecen a las modernas y, en consecuencia, las medidas políticas modernas tampoco deberían parecerse a las antiguas, aplicar esa política confuciana de la benevolencia en este tiempo de terrible inestabilidad social seria como montar un caballo encabritado sin bridas ni fusta, cometiéndose así una insensatez tal que no podría traer sino desastres. ${ }^{41}$

Lisi 李斯 (280-208 AEC), uno de los principales ministros del estado de Qin, llevaría esta idea al extremo, instando al soberano a promover una de las primeras búsquedas intelectuales oficiales de la historia:

$38 \mathrm{Wu}$ Shaomin 武少民 y Zheng Ruixia 郑瑞侠, “论韩非的历史观”, 社会科 学辑刊 n.1 (2001): 108-112.

39 Hanfeizi, cap. 五蠹 [49]: 1. [Traducción de Yao Ning y Gabriel García-Noblejas]

40 André Bueno, "Abolir o passado, reinventar a história: a escrita histórica de Hanfeizi na China do século III a.C.”, História da Historiografia, v.8, n.18 (2015): 29-42; Liu liang 刘亮, “《韩非子》历史思想新探”. 史学理论与史 学史学刊, N.1 (2014): 55-61.

41 Hanfeizi, cap. 五蛽 [49], 5. [Traducción de Yao Ning y Gabriel García-Noblejas] 
Now the August Emperor has unified all under heaven, distinguishing black from white and establishing a single source of authority. Yet the adherents of private theories band together to criticize the laws and directives. Hearing that an order has been handed down, each one proceeds to discuss it in the light of his own theories. At court they disapprove in their hearts; outside they debate it in the streets. They hold it a mark of fame to defy the ruler, regard it as lofty to take a dissenting stance, and they lead the lesser officials in fabricating slander. If behaviour such as this is not prohibited, then in upper circles the authority of the ruler will be compromised, and in lower one's cliques will form. Therefore, it should be prohibited. I therefore request that all records of the historians other than those of the state of Qin be burned. With the exception of the academicians whose duty it is to possess them, if there are persons anywhere in the empire who have in their possession copies of the Odes, the Documents, or the writings of the hundred schools of philosophy, they shall in all cases deliver them to the governor or his commandant for burning. Anyone who ventures to discuss the Odes or Documents shall be executed in the marketplace. Anyone who uses antiquity to criticize the present shall be executed along with his family. Any official who observes or knows of violations and fails to report them shall be equally guilty. Anyone who has failed to burn such books within thirty days of the promulgation of this order shall be subjected to tattoo and condemned to 'wall dawn' [convict] labour. The books that are to be exempted are those on medicine, divination, agriculture, and forestry. Anyone wishing to study the laws and ordinances should have a law official for his teacher.' An imperial decree granted approval of the proposal. ${ }^{42}$

Para los legalistas, por tanto, era necesario acabar con el pasado para reinventar el futuro. Lisi intentó llevar a cabo esta idea durante el reinado de Qin Shihuangdi 秦始皇帝, el único gobernante eficaz de la dinastía Qin. Sin embargo, una serie de medidas violentas e impopulares llevaría a la dinastía a un final pronto, dejando espacio para el surgimiento de la dinastía Han (203 AEC - 221 EC). Los legalistas obtuvieron una sorprendente victoria al lograr la unificación de China bajo el gobierno de la dinastía Qin. Si los legalistas fueron buenos conquistadores, por otro lado, fueron malos administradores, y la tiranía de Qin Shihuangdi no duró mucho. El proyecto institucional de abolir el pasado y reescribir la

42 Sima Qian 司馬遷, Shiji 史記, cap. 秦始皇本紀, 38. [Traducción de Burton Watson] 
historia acompañó la derrota de Qin y eventualmente dejaría espacio para la redención de los confucianos.

\section{Conclusiones}

Sería la dinastía Han la que elevaría la escuela de Confucio al nivel de doctrina estatal, promoviendo una revisión de los textos clásicos antiguos y estableciendo un amplio programa educativo, que hizo del estudio de la historia uno de los elementos fundamentales para la preservación de la cultura. El resultado de esto sería el surgimiento de grandes historiadores como Sima Qian 司馬遷 (145-90 AEC), que reorganizarían la escritura histórica y finalmente la convertirían en uno de los géneros literarios más importantes de la civilización china. ${ }^{43}$

El propósito de esta conclusión es mostrar que, a lo largo del período narrado, la historia se convirtió en un escenario de disputas intelectuales, y las narrativas se manejaron de acuerdo con los conceptos e interpretaciones de cada escuela filosófica. Esta teorización fue crucial en sus propuestas, ya que la comprensión de la historia como un proceso de evolución desde el pasado indicaba cómo la civilización había llegado al estado en que se encontraba y, en consecuencia, qué estrategias deberían adoptarse para resolver los problemas institucionales actuales. De esta manera, la lectura que se hizo de la antigüedad, y la forma en que se enseñó, determinó la conclusión del proceso de construcción de los nuevos métodos filosóficos (dao).

Cabe señalar que las divisiones entre escuelas de pensamiento no siempre fueron tan marcadas como la propia historiografía china proponía, ya que los materiales históricos utilizados fueron de uso común (y casi todos, reeditados por Confucio y por los letrados); la interpretación era lo que variaba. ${ }^{44}$ Pensadores como Laozi y Mozi podrían proponer ideas similares sobre la extinción de la cultura imperante, pero dentro de límites

43 Grant Hard, The worlds of bamboo and bronze: Sima Qian's conquest of history. (Columbia: Columbia University Press, 1999).

44 Wang Keqi 王克奇, “墨子与孔子、老子、韩非关系论”, 孔子研究 n.3 (1997): 91-98. 
bastante diferentes; para Shang Yang y Hanfeizi, la cultura era salvación, pero en una versión diferente y extrema, que situaba al ser humano como principal agente modificador de la naturaleza y del mundo. Finalmente, la inspiración del pasado, en Confucio, parecía la lectura más conservadora de todas, y de alguna manera prevalecería sobre otras; pero la supervivencia de las otras escuelas en la mentalidad china demuestra que no ha habido una derrota total de sus puntos de vista. De hecho, el fértil período intelectual en el que participaron estos autores fomentó una gran diversidad de ideas, que se han convertido en una tradición crítica perdurable en la historia de China.

Junto a los relatos oficiales, que serían publicados por las dinastías posteriores, se produjo un gran número de textos de autores independientes criticando las versiones estatales y proponiendo nuevas formas de entender el pasado. Es lo que Úrsula Richter clasificó como una "tradición anti tradicionalista" en la cultura china, un elemento importante para comprender el pensamiento historiográfico y sus estrategias de escritura. ${ }^{45}$

Con el fin de entender la historia de China es necesario, por lo tanto, aceptar que los pensadores antiguos ya habían encontrado algunos conceptos clave para su lectura crítica: la utilización de marcos teóricos, el redimensionamiento del problema temporal (con la comprensión del anacronismo y de la analogía), la ausencia de intervenciones escatológicas en su dinámica (la historia siempre ha sido y será una actividad humana) y, por último, su uso como instrumento político en la afirmación de discursos intelectuales. Estas consideraciones hicieron que, en la antigua China, la historia fuera un escenario de disputas, en la cual las narrativas -y sus versiones- lucharon por el espacio, la preeminencia y el reconocimiento. De una forma u otra, los pensadores se justificaron a sí mismos basándose en el pasado. El problema de los orígenes, que utilicé como ejemplo aquí, era sólo uno de los muchos temas tratados en la construcción de las propuestas de dichos pensadores para la reforma de la Cultura. El aprendizaje de China, por lo tanto, implica la necesaria comprensión de su diversidad ancestral, expresada en una literatura rica que puede proporcionar interesantes ejemplos de otras tradiciones historiográficas.

$45 \quad$ Ursula Richter, "La tradition de l'antitraditionalisme dans l'historiographie chinoise", Extreme Orient, Extreme Occident, V.9, n.9 (1987): 55-89. 


\section{Referencias}

Bueno, André. "Abolir o passado, reinventar a história: a escrita histórica de Hanfeizi na China do século III a.C." História da Historiografia, v.8, n.18, (2015): 29-42.

Bueno, André. “'Não invento, apenas transmito': reinterpretando a escrita historiográfica de Confúcio”. Anais da X Semana de História Política da UERJ. Rio de Janeiro, 2015.

Bueno, André. “China, uma civilização sem mitos de criação?”. Sinotextos, (2021): 65-81.

Bueno, André. Cem textos de História Chinesa. União da Vitória: Projeto Orientalismo, 2011.

Cheng, Anne. História do Pensamento Chinês. Petrópolis: Vozes, 2009.

Confucio 孔子, Lunyu 論語 [Analectas], https://ctext.org/analects

Cui Qingtan 崔清田. “论墨子学说的体系与中心” [Sobre el sistema y el centro de la teoría Mozi]. 晋阳学刊 [Jinyang Academic Journal], n.6 (2001): 66-71.

Gai Litao 盖立涛, ‘道治与礼治之间—《礼记. 礼运》篇大同小康 关系新论' [ 'Entre la regla del Dao y la regla de los ritos: una nueva teoría sobre la relación entre Datong y Xiaokang' en 'Libro de los ritos - Liyun”']. 哲学动态 [Tendencias filosóficas], n.5 (2017): 5055.

Guo Qiyong 郭齐勇, “《礼记》哲学诠释的四个向度一以《礼 运》 《王制》为中心的讨论' ['Las cuatro dimensiones de la interpretación filosófica del 'Libro de los ritos': debates centrados en los libros 'Liyun' y 'Wangzhi”']. 复旦学报: 社会科学版 [Revista de la Universidad de Fudan: Edición de Ciencias Sociales], n.1 (2016): 41-53.

Han Fei Zi [Hanfeizi 韓非子]. El arte de la Politica. Traducción de Yao Ning y Gabriel García-Noblejas. Madrid: Tecnos, 2010.

Hardy, Grant. The worlds of bamboo and bronze: Sima Qian's conquest of history. Columbia: Columbia University Press, 1999. 
Huang Bo 黄勃 ‘论墨子的’兼爱” [“Sobre el 'Amor Universal' de Mozi”]. 湖北大学学报: 哲学社会科学版 [Revista de la Universidad de Hubei: Edición de Filosofía y Ciencias Sociales], n.4 (1995): 78-85

Jiang Chongyue蒋重跃·辩证发展观在古代中国的觉醒一道儒两家 以'反”为主题的理论探索' [“El despertar de la visión del desarrollo dialéctico en la antigua China: exploración teórica del daoísmo y el confucianismo con el tema de la 'oposición”]. 南京大学学报: 哲 学. 人文科学. 社会科学 [Revista de la Universidad de Nanjing: Filosofia, Humanidades y Ciencias Sociales] n.5 (2015) 64-91.

Jullien, François. A propensão das coisas: por uma história da eficácia na China. São Paulo: Ed. UNESP, 2017.

Keightley, David. Sources of Shang History: The Oracle Bone Inscriptions of Bronze Age China. Berkeley: University of California Press, 1985.

Lao Tsé [Laozi 老子]. Tao te Ching: Los Libros Del Tao. Edición y Traducción del chino de Iñaki Preciado Idoeta. Madrid: Trotta, 2012.

Levi, Jean. Los funcionarios divinos: politica, despotismo y mistica en la China antigua. Madrid: Alianza, 1991.

Liji 禮記: Lijing: Tratado de los Ritos, vol. I (Libros I-VIII). Traducción de Fulvio Scarcia y Leonardo La Rosa. Madrid: Universidad Carlos III de Madrid, 2021. Disponible en: https://www.academia. edu/18423263/Lijing_Tratado_de_los_Ritos_Vol_I_Libros_I_ VIII_

Lin Xiaoping 林晓平， ‘春秋战国时期史官职责与史学传统” ["Las responsabilidades de los historiadores y la tradición de la historiografía en la primavera y el otoño y el período de los estados guerreros”]. 史学理论研究 [Estudios teóricos de la historiografía], n.1 (2003): 59-69.

Liu Liang 刘亮, “《韩非子》历史思想新探' [“Una nueva exploración de pensamientos históricos en 'Han Feizi””]. 史学理论与史学史学 刊 [Revista de teoria da historia e historiografia] n.1, (2014): 55-61.

Liu Xie 刘妿思. El corazón de la literatura y el cincelado de dragones [文心 雕龙]. Traducción, introducción y notas de Alicia Relinque Eleta. Granada: Editorial Comares, 1995. 
Mo Ti [Mozi 墨子]. Politica del amor universal. Traducción de Carmelo Elorduy. Madrid: Tecnos, 1987.

$\mathrm{Ng}$ On-Cho y Edward Wang. Mirroring the past: the writing and use of history in imperial China. Honolulu: University of Hawai Press, 2005.

Norden, Brian. Introdução a filosofia chinesa clássica. Petrópolis: Vozes, 2018.

Pei Chuanyong裴传永, ‘大同小康之论提出者诸说辨误' [“Distinguir los errores de los proponentes de la teoría de Datong-Xiaokang”]. 孔 子研究 [Estudios Confucianos], n.2 (2020): 97-108.

Pei Chuanyong 裴传永, ‘大同小康之论非关孔子辨” [ “La teoría de Datong-Xiaokang no está relacionada con Confucio”]. 孔子研究 [Estudios Confucianos], n.6 (2003): 12-21.

Qian Yongshen 钱永生 ‘墨子人本思想的结构’ [“La estructura del pensamiento humanista de Mozi”]. 湖南大学学报: 社会科学版 [Revista de la Universidad de Hunan: Edición de Ciencias Sociales], n.1 (2009): 5-10.

Richter, Ursula. "La tradition de l'antitraditionalisme dans l'historiographie chinoise". Extreme Orient, Extreme Occident. v.9, n.9 (1987): 55-89.

Shang Yang 商鞅. The Book of Lord Shang. Traducción de Jan Julius Lodewijk Duyvendak. Chicago: University of Chicago Press, 1963 [reimpresión].

Shujing 書經 [Shangshu 尚書], Disponible en: https://ctext.org/shangshu

Sima Qian 司馬遷. Records of the Grand Historian: Qin Dynasty. Traducción de Burton Watson. Research Center for Translation, The Chinese University of Hong Kong and Columbia University Press, 1993.

Sui Shufen 隋淑芬, “法治社会的建构——论商鞅的社会理想? [“ $\mathrm{La}$ construcción de una sociedad regida por la ley: sobre el ideal social de Shang Yang”]. 贵州社会科学 [Guizhou Ciencias Sociales], n.6 (2005): 58-61. 
Vandermeersch, Leon. Études Sinologiques. Paris: Presses Universités de France, 1994.

Wang Keqi 王克奇 ‘墨子与孔子、老子、韩非关系论’ [“Sobre la relación entre Mozi y Confucio, Laozi y Han Fe”]. 孔子研究 [Estudos Confucianos], n.3 (1997): 91-98.

Wu Fei 吴飞 ‘《礼运》首章再考辨” [“Reexamen del primer capítulo de 'Liyun”]. 传统中国研究集刊 [Revista colección de estudios tradicionales chinos], n.19 (2018).

Wu Shaomin 武少民 y Zheng Ruixia 郑瑞侠 '论韩非的历史观” [“Sobre la visión de la historia de Han Fei”]. 社会科学辑刊 [Revista de Ciencias Sociales], n.1 (2001): 108-112

$X u n z i$ 苟子, Disponible en: https://ctext.org/xunzi

Yang Xiaoming 杨朝明, “《礼运》大同说的实质与意义' “'La esencia y el significado de la doctrina Datong en 'Liyun””]. 衡水学院学报 [Revista de la Universidad de Hengshui], n.6 (2016), 31.

Zeng Zhenyu 曾振宇 “商鞅法哲学研究” [“Investigación de la filosofía de las leyes de Shang Yang”]. 史学月刊 [Historia mensual], n.6 (2000): 26-33.

Zhang Weyan 张文彦, “论先秦儒家与道家的自然观及历史观' ["Sobre las visiones de la naturaleza y la historia en el confucianismo y el taoísmo en la dinastía Pre-Qin”]. 史学理论研究 [Estudios teóricos en la bistoriografia] n.3 (2003): 61-65.

Zhuangzi 莊子. Maestro Chuang Tsé. Traducción de Iñaki Preciado Idoeta. Barcelona: Kairós, 1996. 